\title{
Mindset effects on information search in self-evaluation
}

\author{
UTE C. BAYER ${ }^{1 *}$ AND PETER M. GOLLWITZER ${ }^{1,2}$ \\ ${ }^{1}$ University of Konstanz, Germany \\ ${ }^{2}$ New York University, USA
}

\section{Abstract}

Research on mindset theory (Gollwitzer \& Bayer, 1999) observed that people in an implemental mindset show an orientation towards positive illusionary self-evaluations, whereas people in a deliberative mindset opt for accurate self-evaluations. In the present study, we tested whether these self-evaluative orientations and the associated search for certain types of self-relevant information (feedback) are moderated by low versus high self-views. With high self-view participants we observed the hypothesized mindset effects on information search, but we obtained the reverse pattern for low self-view participants. The latter finding points to self-defensiveness in low self-view individuals. Implications are discussed in terms of the consequences of accurate versus positive illusionary selfevaluations for the successful control of goal pursuits, and individual differences in mindset effects.

Self-evaluation is guided by different motives or purposes (Pomerantz, Saxon, \& Kenney, 2001; Sedikides \& Skowronski, 2000; Sedikides \& Strube, 1997). First, a concern for self-assessment motivates people to reduce uncertainty about their abilities and personal attributes. This is achieved by performing high diagnostic tasks and searching for diagnostic information (Trope, 1986). Second, people's self-evaluations also serve self-enhancement concerns. The self is protected from negative information by selectively processing positive information. The valence of feedback and the personal importance of the attribute in question are of primary importance. People guided by self-enhancement concerns will thus find information diagnostic of success, high ability, or any other positive personal attribute to be more attractive than information diagnostic of failure, low ability, or any other negative personal attribute (Brown \& Dutton, 1995; Kunda, 1990; Taylor \& Brown, 1988).

Third, people's self-evaluations are also guided by self-verification concerns which aim at endorsing preexisting self-conceptions. Self-verification applies to both positive and negative aspects of the self. People seek verification of their certain self-concepts to a larger degree than their uncertain self-concepts. What matters is the consistency between self-concept and feedback rather than selfconcept valence or feedback valence (Swann, 1990, 1997). Finally, people are motivated to improve their traits, abilities, skills, health status, or well-being. This motive is conceptually different from the 
other three motives (Taylor, Neter, \& Wayment, 1995). Self-improvement focuses on genuine improvement, which does not necessarily include self-concept positivity. Attempts at self-improvement will result in a sense of progress, hope, or growth (Collins, 1996; Wheeler, 1966).

Operating on the basis of one or the other of the four described concerns of self-evaluation has differential consequences for the type of self-knowledge that accrues, each of which comes with its typical advantages and usefulness (Sedikides \& Skowronski, 2000). Serving self-assessment concerns leads to accurate self-knowledge which makes it easier for people to select tasks that will not overtax them. Serving self-enhancement concerns, on the other hand, leads to favourable self-concepts which strengthen people's resilience in overcoming barriers to their goal pursuits and in dealing with everyday hardships. Serving self-verification concerns leads to stable self-views that allow for easy predictability of one's future behaviours (and the reactions of others towards us). Finally, selfimprovement focuses on self-betterment regardless of self-concept accuracy.

Even though the four self-evaluation concerns listed are rather pervasive and accompany almost all of people's daily pursuits, researchers have started to search for those variables that favour one of these concerns over the other. For instance, it was observed that feeling uncertain about one's abilities (Trope \& Bassok, 1982), feeling good about oneself in general (Trope \& Neter, 1994), and placing a good deal of importance to be competent in a particular area (Trope \& Pomerantz, 1998) strengthen the self-assessment orientation. Self-verification concerns, on the other hand, are the more prevalent the more certain people are of their self-conceptions, as people are motivated to defend their existing self-concepts against threats (Swann \& Ely, 1984). With respect to self-enhancement it was observed that this concern is particularly strong in people with high self-esteem (Wayment \& Taylor, 1995), and when the personal attribute implied is perceived as fixed and nonmodifiable (Dunning, 1995). Finally, feelings of threat or inadequacy are more likely to instigate the self-improvement motive. It was observed that upwards comparisons for the purpose of self-improvement occur frequently when people have to cope with novel situations (e.g. in coping with cancer, Taylor, Aspinwall, Guilano, Dakof, \& Readon, 1993; performance on novel tasks, Buunk, 1995).

\section{MINDSETS AS MODERATORS OF SELF-ENHANCEMENT AND SELF-ASSESSMENT CONCERNS}

Taylor and Brown (1988) proposed that a mentally healthy person is characterized not by accurate assessments of her or his qualities but typically by holding mildly self-aggrandizing perceptions of the self. They argued that instead of being maladaptive these positively distorted self-perceptions actually foster positive self-regard, the ability to care for and about other people, the capacity for creative and productive work, and the ability to effectively manage stress. Despite the obvious positive consequences of moderate self-enhancement, these findings raise the disturbing question: How do people with inflated self-concepts effectively identify and make use of negative feedback they may encounter in the world? One potential resolution is the possibility that there may be times when people are more honest with themselves, during which they recognize and incorporate negative feedback.

Mindset theory (Gollwitzer, 1990, 2003) suggests a set of circumstances" when such a window to realism opens up. It is argued that successful goal pursuit involves solving four consecutive tasks: choosing between potential goals, planning the implementation of a chosen goal, acting on the chosen goal, and evaluating what has been achieved. When people get involved in these tasks, different cognitive procedures are said to become activated (i.e. different mindsets) which make it easier to live up to the respective task demands. More specifically, it is argued that deliberation in the predecisional phase involves the careful appraisal of whether one could pursue (or not) a potential goal. Therefore, 
the pros and cons in regards to the potential goals have to be weighted and the feasibility of these goals has to be assessed. Consequently, the respective cognitive procedure (i.e. the deliberative mindset) should foster relatively even-handed-and accurate appraisals of evidence. With respect to selfassessment concerns, mindset theory predicts that the deliberative mindset should foster the accurate analysis of feasibility-related information on potential goals.

Planning the implementation of a chosen goal, however, poses a problem associated with different task demands. Deliberation of the goal in question needs to be ended and people need to look toward implementation. Good opportunities need to be discovered and linked to appropriate goal-directed behaviours (i.e. plans need to be made with respect to when, where, and how one wants to act). Consequently, the respective cognitive procedure (i.e. the implemental mindset) should foster a biased analysis of feasibility and desirability-related information so that deliberation of the goal will not start anew. The person starts to conceive of the feasibility of chosen goals in an overly optimistic way and views the desirability of the chosen goal in a partial manner (i.e. sees more pros than cons). Moreover, people tune in to implementation-related information as it is needed to get started on one's goals.

A research programme aimed at testing the proposed different cognitive features of the deliberate and implemental mindset reported by Gollwitzer and Bayer (1999; Gollwitzer, 2003). In this research, the deliberative mindset was induced by asking participants to either extensively deliberate an unresolved personal problem by listing the short-term and long-term pros and cons of both making and not making a goal decision. For the implemental mindset, participants were asked to list the five most important steps of implementing a chosen goal, and then to specify, when, where, and how they intent to execute each step. Thereafter, both the deliberating and planning participants were asked to perform presumably unrelated intellectual tasks (usually performed by a different experimenter in a different situational context).

Indeed, research participants placed into an implemental mindset (by asking them to plan the implementation of an important life decision they had already made) reported strong illusions of control over frequent, but uncontrollable outcomes in a classic contingency learning task (Alloy \& Abramson, 1979), whereas deliberative mindset participants (who had to contemplate the pros and cons of making a major life decision) indicated reduced illusions (Gollwitzer \& Kinney, 1989). Taylor and Gollwitzer (1995) explored the influence of deliberative and implemental mindsets on several other self-relevant judgments. It was again observed that participants in the deliberative mindset were in a position to open a window to realism and thus reported a less positive illusionary standing on various personal attributes (e.g. cheerfulness, academic ability), as well as less positive illusionary judgments of their invulnerability to controllable (e.g. divorce, having a drinking problem) and uncontrollable risks (e.g. developing a heart disease, loosing a limb). More recently, Armor and Taylor (2003) reported that implemental mindsets do not only produce enhanced self-efficacy, optimistic outcome expectations, and perceptions of the task at hand as easy, but also could show that these positive illusions helped people to succeed at the task at hand.

\section{INDIVIDUAL DIFFERENCES IN MINDSET EFFECTS: THE IMPACT OF LOW/HIGH SELF-VIEWS}

Meanwhile, research on mindsets has addressed individual differences in the activation of deliberative and implemental mindsets and their effects on cognition and behaviour. For instance, mindset effects have been found to be dependent on a person's achievement motivation (Pucca \& Schmalt, 2001), social anxiety (Hiemisch, Ehlers, \& Westermann, 2002), and goal commitment (Gagné \& Lydon, 2001). In the present study, we investigate the impact of a person's low/high self-view as a potential 
moderator of mindset effects. More specifically, we investigate the search for self-relevant information by deliberative versus implemental participants holding either a high or low self-view.

As Trope and Neter (1994) have pointed out, the processing of feedback about one's abilities has two types of consequences: At an informational level, people learn about their standing on the respective ability. At an emotional level, positive feedback induces positive feelings (i.e. pride) and negative feedback leads to negative feelings (i.e. self-threat, disappointment, and self-doubts). According to Trope and Neter, people consider such potential costs and benefits of self-relevant information and their processing of self-relevant information guided by these anticipated positive and negative consequences.

Following a cost-benefit perspective, it depends on a person's low versus high self-concept whether self-assessment or self-enhancement concerns are served in deliberative and implemental mindsets. With individuals holding a high self-concept, self-assessment concerns triggered by a deliberative mindset are emotionally not very risky as she or he rightfully anticipates positive feedback. And serving self-enhancing concerns in the implemental mindset is informationally not very risky as positive illusions help the individual to implement the chosen goal (Armor \& Taylor, 2003).

Things are quite different with individuals holding low self-views. The accuracy orientation triggered by the deliberative mindset should create a state of self-threat in these individuals, as chances are high that they will have to face weaknesses. Accordingly, they should refuse to process information accurately and instead serve self-improvement/self-enhancement concerns. Moreover, for participants holding a low self-view the positive illusions triggered by the implemental mindset are inconsistent with their self-view and thus should create a fear of invalidity. Accordingly, they should not serve selfenhancement concerns but modestly stick to an assessment orientation.

These predictions are in line with recent research on deliberative and implemental mindsets that looks at individual differences as potential moderators of mindset effects. For example, Pucca and Schmalt (2001) analysed the effects of a person's achievement motive (fear of failure vs. hope of success) on thought content in deliberative and implemental mindsets. Participants either had to deliberate which of two different complex reaction time tasks they wanted to perform (deliberative mindset) or to choose one of these tasks and then plan task performance of the chosen task (implemental mindset). Interestingly, the classic finding of an optimistic bias in thought content in implemental as compared to deliberative individuals (Heckhausen \& Gollwitzer, 1987; Taylor \& Gollwitzer, 1995, Study 3) was moderated by the achievement motive. Whereas hope of success individuals showed the classic pattern, the reverse was true for fear of failure individuals: The latter reported more thoughts about strengths than about weaknesses in performing the difficult vigilance task in a deliberative mindset, and reported more thoughts about weaknesses rather than strengths in an implemental mindset. Apparently, chronic fear of failure individuals dealt with the self-threat triggered by a deliberative mindset by boosting their self-perception of competence. And chronic fear of failure individuals responded to the optimistic orientation (hopes) triggered by the implemental mindset with intensifying their fear of failure (i.e. thinking of having chosen the wrong task).

Hiemisch et al. (2002) placed people with high versus low social anxiety in deliberative and implemental mindsets and measured their processing of deliberative (i.e. pros and cons of choosing a goal) versus implemental information (i.e. when, where, and how of goal pursuit) in solving a critical interpersonal problem. Low socially anxious people showed better procêssing of implemental as compared to deliberative information in the implemental mindset and equal processing in the deliberative mindset. High socially anxious people, on the other hand, processed deliberative information better than implemental information in the implemental mindset, whereas the reserve was true for the deliberative mindset. The authors suggest that socially anxious people coped with the threat of the deliberative mindset (having to look not only on strengths but also on weaknesses) by committing themselves to a certain way of solving the interpersonal problem at hand, thus entering an implemental 
mindset that protected them from having to look at their weaknesses. Socially anxious people who were in an implemental mindset to begin with, on the other hand, quickly discovered problems of solving the social problem at hand (because of their social anxieties) which in turn triggered deliberation of what kind of alternative goals they had better pursued. Thus, they entered a deliberative mindset which facilitated the processing of deliberative information.

Finally, Gagné and Lydon (2001) suggest that deliberation of goal decisions that have already been made can initiate defensive processing of information rather than accurate processing. In one study, they asked participants highly committed to a romantic relationship to deliberate this relationship decision or a nonrelationship goal decision. They found that when asked to rate how their partner compared with the average, those individuals asked to deliberate over the relationship goal decision gave much higher ratings than those who were asked to deliberate over a nonrelationship goal decision. Of interest, these ratings were also higher than those of implementation participants who had been planning the implementation of the relationship goal.

Gagné and Lydon suggest that the deliberation of a relationship goal decision may have been perceived as threatening, resulting in an enhancement of the partner's positive attributes. Testing this idea, they assessed the degree of commitment participants felt to their relationship in a second study and hypothesized that high commitment participants should feel more threatened by the deliberative mindset than low commitment participants. Indeed, they found that high commitment but not low commitment participants defended against a threat of a deliberative mindset by increasing their positive views of their partner.

\section{SEEKING INFORMATION ON INTELLECTUAL CAPABLITY IN DELIBERATIVE VERSUS IMPLEMENTAL MINDSETS}

In the present study, we assess whether high versus low self-view individuals differentially serve selfassessment, self-enhancement/improvement and self-verification concerns when placed in a deliberative versus an implemental mindset. The strengths of these concerns can be assessed via the strategies people use to gather self-relevant information (Kunda, 1990; Trope \& Liberman, 1996). For example, in the service of self-enhancement, people spend more time reading favourable than unfavourable information about themselves (Baumeister \& Cairns, 1992), and they search for ability-relevant information more intensively when they have reason to believe that they will gain positive rather than negative information about themselves (Brown, 1990). In the service of selfverification, people seek that kind of feedback (positive or negative) that they believe will confirm their self-concepts. For instance, people prefer interaction partners from whom they expect to receive confirmatory feedback with respect to their positive and negative attributes (Swann, Stein-Seroussi, \& Giesler, 1992). A diagnostic strategy of information search, on the other hand, leads people to ask high over low diagnostic questions (Trope \& Bassok, 1982) or to choose high over low diagnostic tasks (Brown, 1990; Strube et al., 1986). Moreover, a diagnostic orientation is indicated by the extent to which favourable and unfavourable information is sought in an even manner (Trope \& Neter, 1994). A self-improvement strategy is commonly investigated in terms of upward social compärisons as such comparisons provide a standard to strive for and offer an inspiration to meet the goal (Collins, 1996).

It is seldom the case that the strength of the different self-evaluation concerns is measured in one and the same study (Sedikides, 1993). In the present study, we constructed a feedback questionnaire that allowed determining the extent to which the participants are guided by self-enhancement, selfverification, or self-assessment concerns. This questionnaire offered favourable and unfavourable feedback, and at the same time varied the diagnosticity of this feedback (Devine, Hirt, \& Gehrke, 
1990). The personal attribute we focused on was intellectual abilities, and thus we analysed a attributespecific self-view. We consider this attribute to be of high personal importance. Accordingly, selfdefensiveness with respect to having to admit that one is low on this attribute should be rather high.

All participants were informed that they would take part in two different experiments. In the presumed first experiment, they worked on an ostensible personality and ability test which involved questions about five personal attributes including the critical aspect of intellectual skills. In the presumed second experiment, participants worked on a task designed to induce either the deliberative or implemental mindset. Thereafter, we offered the participants feedback on their intellectual abilities. Participants were asked to indicate their preference with respect to eight aspects of possessing or lacking intellectual abilities (four aspects related to strengths, and four to weaknesses; half of the strengths and weaknesses related questions were diagnostic, the other half nondiagnostic).

We interpret a general preference for information on strengths over weaknesses as serving selfenhancement concerns. Serving self-assessment concerns in contrast is indicated if participants choose high diagnostic information over low diagnostic information, and if they choose information about strengths and weaknesses in an even manner. Finally, serving self-verification concerns is indicated when participants with low self-views prefer information on weaknesses over strengths and participants with high self-views prefer information on strengths over information on weaknesses.

We expected that participants holding a high self-view should be guided in their information search by self-assessment concerns in a deliberative mindset and by self-enhancement concerns in an implemental mindset. For participants holding a low self-view we expected an inverse pattern: Their preferences for self-relevant information should be guided by self-defensiveness. Feelings of selfthreat triggered in the deliberative mindset should lead to self-enhancement/improvement concerns in the deliberative mindset and fear of invalidity triggered in the planning mindset should lead to assessment concerns in the implemental mindset.

\section{METHOD}

\section{Participants}

Fifty two students (26 female and 26 male) of a German university participated in this research for a credit of $7.5 €$ (approx. \$7). A questionnaire measured participants' self-view of possessing intellectual capability as done in earlier studies on self-verification (Swann \& Ely, 1984; Swann, Pelham, \& Chidester, 1988). Only those individuals who scored either in the upper third $(N=18$; high self-view participants) or the lower third ( $N=18$; low self-view participants) in respective self-ratings were included in the data analysis based on a four-factorial ANOVA (see below); following the research on self-verification theory (Swann et al., 1992), the middle group of participants $(N=16$; moderate self-view participants) was excluded.

\section{Procedure}

Participants were contacted on campus. They appeared at the laboratory in groups of four to six. On arrival, the first experimenter informed participants that during the next hour they would engage in two separate unrelated experiments. Before starting the first study, the experimenter asked all participants if they were willing to take part in an additional survey. She informed participants that the questionnaire was used to learn more about college students. All participants agreed and filled out 
the additional questionnaire. One part of the survey included the Self-Attributes Questionnaire (SAQ) developed by Pelham and Swann (1989). This instrument taps people's self-views on five attributes (i.e. intellectual capability, physical attractiveness, social competence, artistic and/or musical ability, and competence in sports). For each of the five SAQ attributes participants rated themselves as compared to other college students of the same age on a scale from 1 (bottom 5\%) to 10 (top 5\%). Later we analysed their self-ratings in regard to their intellectual capability. When the participants had filled out the survey questionnaire, the experimenter informed the participants that the local organizational psychology research group had developed new intervention programmes to enhance people's performance in work settings. These different kinds of training programmes would first be tested with college students. Half of the participants then received a booklet that entailed instructions on how to deliberate an unresolved personal problem, whereas the other half received a booklet with instructions on how to plan the implementation of a pressing goal project.

The deliberative and implemental mindsets were induced by a procedure developed by Gollwitzer and colleagues (Gollwitzer \& Kinney, 1989; Gollwitzer, Heckhausen, \& Steller, 1990). To induce a deliberative mindset, participants were asked to first name an important unresolved personal problem in their everyday life. It should have the format of 'Should I do x or not?' Moreover, this potential goal should be an important one and acting on it should be rather complex (i.e. several action steps are necessary to realize it). After participants had named their unresolved problem, they were to rate various features of the potential goal: feasibility ('How likely is it that you will attain this potential goal?') and desirability ('How important is it that you will attain this potential goal?'). Answer scales ranged from 1 (not likely or important) to 9 (very likely or important). Participants then started deliberation by writing down immediate and long-term positive and negative consequences of making a change decision (i.e. a decision to attain $\mathrm{x}$ ). In addition, they were asked to consider immediate as well as long-term positive and negative consequences of a decision to stay with the status quo (i.e. a decision not to pursue $\mathrm{x}$ ). To help participants follow the instructions, they first practised this deliberation procedure on a sample problem: 'Should I go on a vacation or not?' In addition, participants had to indicate on a straight line (which was marked in the middle with 'point of decision,' at the left end-point with 'far from a decision,' and at the right end-point with 'far after making a decision') where exactly they felt with respect to having made a decision. This procedure was used to detect participants who no longer deliberated an unresolved personal problem.

To induce an implemental mindset, participants were asked to name an important personal project they intended to realize in the following 3 months. It should have the format of 'I intend to do $x$ !' It was pointed out that participants should name projects to which they felt committed for quite some time, and refrain from forming new commitments on the spot. After participants had named their projects, we asked for the goal attributes of feasibility and desirability (items were the same as in the deliberative mindset condition). Finally, participants were requested to decide on how they intended to realize their goal projects. They first had to delineate the five most important action steps and then to decide for each of these steps, when, where, and how they wanted to get started with its implementation. To help participants follow instructions, they first had to practise this planning procedure on a sample project: 'I intend to go on a vacation!' On average, participants worked on these presumed training programmes for $20 \mathrm{~min}$. Thereafter, the first experimenter left and the second experimenter entered the laboratory.

The second experimenter informed participants that the purpose of her study would be to develop a new personality and ability test to be performed on a PC. Participants would work on this test in a selfpaced manner and they could even choose between test materials depending on what type of skill they wanted to be tested. To learn more about the specific test preferences of each student, she asked participants to fill out a simple questionnaire. This questionnaire consisted of eight questions enquiring about academic skills. Four questions focused on strengths and four on weaknesses. Moreover, two 
questions on strengths were highly diagnostic with respect to intellectual capability (e.g. 'Do I quickly find creative solutions?'), the others were low on diagnosticity (e.g. 'Do I talk fast?'). The four questions concerning weaknesses also varied with respect to the diagnosticity of assessing intellectual capability. Two questions were highly diagnostic (e.g. 'Do I have difficulties in understanding complex problems?'), and two were of low diagnosticity (e.g. 'Do I have difficulties in using punctuation marks?'). Participants were asked how interested they were in receiving answers to these questions. They answered each question on a 7 point scale $(1=$ not interested at all; $7=$ very interested). At last, all participants received a final questionnaire including several manipulation check questions. Thereafter, the participants were thoughtfully debriefed with special emphasis on the fact that the test construction cover-story was entirely fictitious.

\section{RESULTS}

\section{Equivalence of Groups}

In a first step, we tested if the participants chose comparable potential goals and set goals in the deliberative and implemental mindset condition, respectively. Goals were compared in regards to their attractiveness and feasibility, but no significant differences were observed (attractiveness: $M=6.73$ vs. $M=7.36, p>0.15$; feasibility: $M=6.72$ vs. $M=7.27, p>0.25$ ).

\section{Differential Prevalence of Self-enhancement, Self-verification, and Self-assessment Concerns in the Deliberative and Implemental Mindsets}

We analysed the interest in self-relevant information in relation to mindset, the diagnosticity and valence of information, and participants' self-view computing a four-factorial ANOVA on participants' preferences for information on their intellectual capability. The two between-factors were mindset (deliberative vs. implemental) and self-view (low vs. high), and the two within-factors were valence of information (strengths vs. weaknesses) and diagnosticity of information (high vs. low). This analysis showed a significant four-way interaction effect, $F(1,32)=6.77, p=0.01$.

Looking only at participants with a high self-view, we observed a significant three-way interaction between the factors of deliberative versus implemental mindset, seeking diagnostic versus nondiagnostic information, and seeking information about strengths versus weaknesses, $F(1,18)=4.95$, $p<0.05$. As the means in Figure 1 reveal, deliberative mindset participants preferred high diagnostic information over low diagnostic information in regard to both strengths, $t(8)=4.02, p<0.01$, and weaknesses, $t(8)=6.65, p<0.001$. Moreover, they wanted to receive high diagnostic information about strengths as much as high diagnostic information about weaknesses, $t(8)=1.10, p=0.24$. Only with respect to low diagnostic information was there a preference for strengths over weaknesses, $t(8)=2.50, p<0.05$.

Implemental mindset participants preferred information on strengths over information on weaknesses, $M=5.05$ versus $M=4.36, t(8)=2.62, p<0.05$. Moreover, they preferred highly diagnostic information about strengths over highly diagnostic information about weaknesses, $t(8)=3.31$, $p=0.01$, as well as low diagnostic information about weaknesses, $t(8)=4.15, p<0.01$, and low diagnostic information about strengths, $t(8)=5.32, p<0.001$.

The results for the participants with a low self-view presented a different pattern (see Figure 2). Only the main effect of diagnosticity, $F(1,18)=18.05, p=0.001$ (indicating a general preference for 


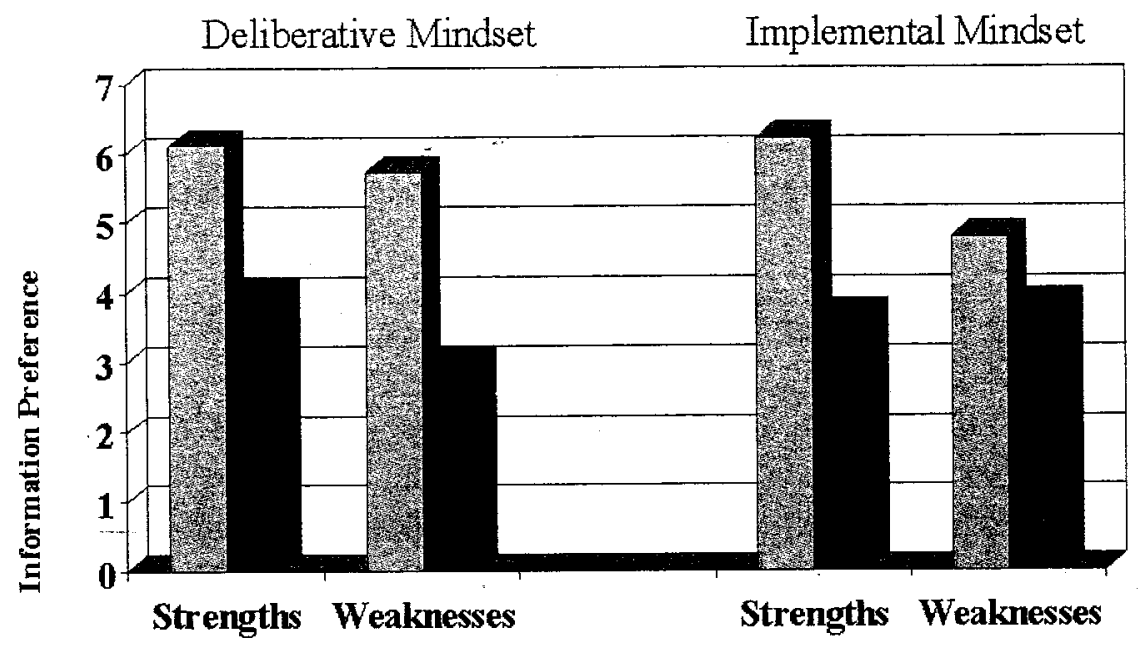

图 High Diagnostic Information 1 Low Diagnostic Information

Figure 1. Information search by participants with a high self-view of intellectual capability

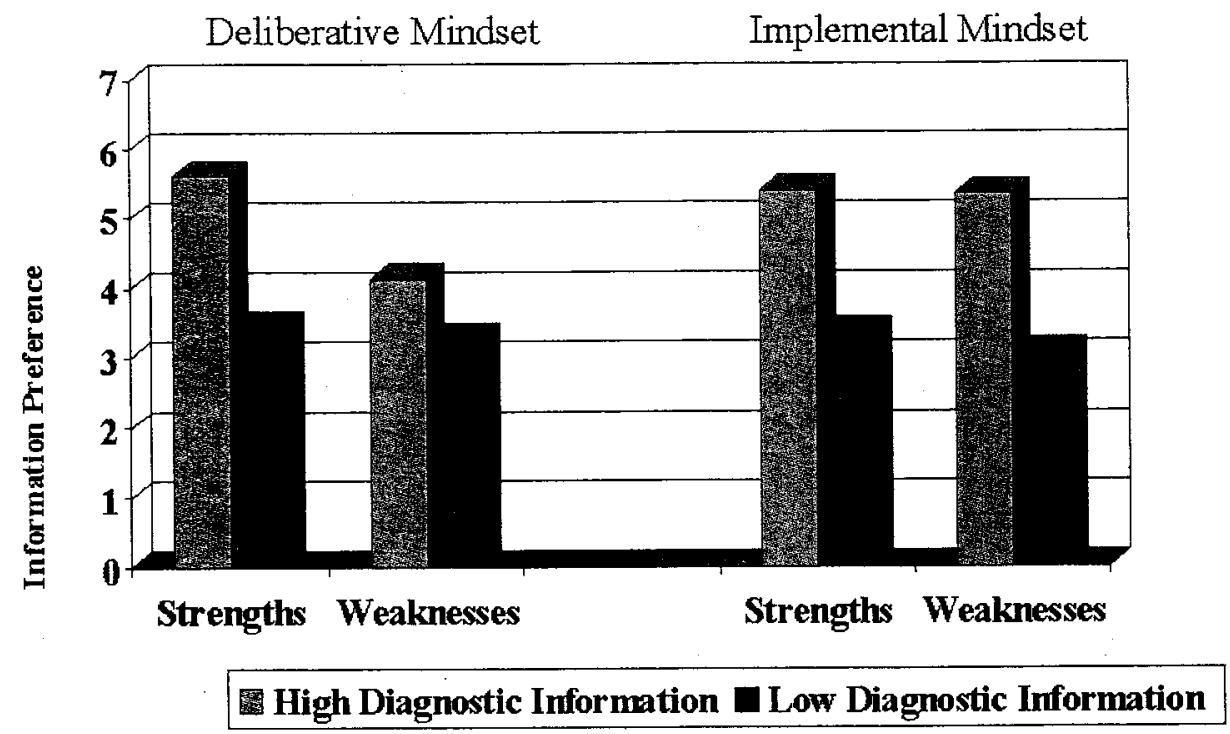

Figure 2. Information search by participants with a low self-view of intellectual capability

high diagnostic information) and the main effect of valence of information (indicating a general preference for strength over weaknesses) were significant, $F(1,18)=4.43, p=0.05$. None of the possible interaction effects reached significance, all $F \mathrm{~s}>0.15$.

In the deliberative mindset, low self-view participants preferred information about strengths compared to information about weaknesses, $M=4.52$ versus $M=3.69, t(8)=2.5, p<0.05$, and high diagnostic information over low diagnostic information, $M=4.86$ versus $M=3.36, t(8)=2.42$, $p<0.05$. Low self-view participants in the implemental mindset only revealed a significant preference for high diagnostic information over low diagnostic information, $M=5.36$ versus $M=3.19$, $t(8)=3.61, p<0.01$.

As a final analysis, we computed a three-factorial (valence of information, diagnosticity of information, and mindset) ANOVA using the self-view ratings as a continuous covariate rather than a dichotomous between-factor. This analysis included all of the 52 participants, and not just those 
participants who placed themselves either in the lower or upper tertile of the self-view ratings. Supporting the results of the four-factorial ANOVA, we observed that the significant three-way interaction of valence of information, diagnosticity of information, and mindset, $F(1,48)=6.21$, $p<0.02$, was qualified by an interaction with the covariate; $F(1,48)=6.20, p<0.02$.

\section{DISCUSSION}

Mindset effects on information search about a specific personal attribute (e.g. intellectual capability) interact with a person's self-view of possessing this attribute. High self-view participants (i.e. participants who believe to possess this attribute to a large degree) prefer high over low diagnostic information in a deliberative mindset, and this with respect to relevant strengths and weaknesses. This type of information search is indicative of the presence of self-assessment concerns. High self-view participants in an implemental mindset prefer information on strengths over information on weaknesses. This type of information search is indicative of the presence of self-enhancement concerns. In sum, participants with a high self-view solicit information in a way that allows for both the setting of realistic goals and the persistent implementation of chosen goals. Their pre- and postdecisional information search creates an opportunity structure that will lead to positive performance outcomes that ultimately confirm (i.e. verify) their high self-views.

A different pattern of information search is observed in participants with a low self-view. In the deliberative mindset, self-assessment concerns were accompanied by self-enhancement concerns (i.e. a general preference for information on strengths over weaknesses). In the implemental mindset, selfassessment concerns were prevalent (i.e. diagnostic information was preferred over nondiagnostic information for strengths and weaknesses alike). In sum, participants with a low self-view solicit information in a way that hampers both the setting of realistic goals and the persistent implementation of chosen goals. This kind of opportunity structure will hamper positive performance outcomes and thus ultimately confirm (i.e. verify) their low self-views.

\section{The Resource Explanation of Diagnostic Information Search}

A self-assessment orientation is enhanced if people are in a good mood or have received prior positive feedback (Trope \& Neter, 1994; Trope, Ferguson, \& Raghunathan, 2001). Trope and colleagues argue that a self-assessment orientation is associated with potential emotional costs (i.e. to regulate negative feelings associated with accurately processing negative feedback). Thus, being in a good mood or having received positive information may be seen as resources (Aspinwall, 1998) that make it easier to face negative feedback. As we observed a self-assessment orientation in the deliberative mindset for participants with a high self-view only, one could argue that a high self-view served as a resource which facilitated a self-assessment orientation. A similar argument can be made on the basis of Brown's (1990) findings that positive outcome expectations also facilitate an assessment orientation.

Still, such resource-related perspectives only manage to interpret our findings for high self-view participants in a deliberative mindset. They fail to account for the fact that high self-view individuals serve self-enhancement concerns rather than self-assessment concerns when placed in an implemental mindset. Interpreting a high self-view as a resource would have to predict the same self-assessment orientation in both the deliberative and the implemental mindset. Adding a mood-as-resourceperspective would even have to predict stronger self-assessment concerns in the implemental mindset than in the deliberative mindset, as implemental mindsets have been found to be more strongly 
associated with positive moods than deliberative mindsets (Taylor \& Gollwitzer, 1995). In sum, while a resource perspective can only account for the observed self-assessment orientation of deliberative mindset participants with a high self-view, mindset theory accounts for the differences between deliberative and implemental mindset participants with a high self-view.

\section{Are Serving Self-Enhancement Concerns Indeed Beneficial to Goal Attainment?}

We suggest that implemental mindset participants' opting for self-enhancement facilitates the implementation of chosen goals. But do they really? There exists a bulk of evidence that speaks to the benefits of positive illusions. For example, Wright (2000) reports that positive illusions about academic skills enhance academic performance. Moreover, positive illusions about one's relationship stabilize it (Murray \& Holmes, 1997), and positive illusions about one's ability, vulnerability to risk, and likelihood of future events increase psychological and physical well-being (Kwan, Love, Ryff, \& Essex, 2003; Taylor \& Brown, 1988). Finally, with serious illnesses (e.g. AIDS) positive illusions manage to hamper illness progression (Taylor, Kemeny, Reed, Bower, \& Gruenewald, 2000).

These findings have been criticized in the realism versus optimism debate (e.g. Colvin \& Block, 1994; Robins \& Beer, 2001). However, this controversy has mainly focused on how to measure illusionary optimism in a valid and reliable manner, and whether the proclaimed positive effects are interpersonal or intrapsychic, specific or general, only short-term or even long-term (e.g. Paulhus, 1998). At no point in this controversy, however, was the more modest position (proposed by classic research on motivation; Atkinson, 1957; Bandura, 1982; Mischel, 1973) that high self-views are motivationally more effective than low self-views.

\section{Pre- and Postdecisional Information Search in Low Self-View Individuals}

When low self-view individuals are placed in a deliberative mindset having to face their weaknesses they should experience a strong ego-threat. In an attempt to protect the self against this threat, they may focus on their strengths. But this self-defensive move is a handicap for goal selection as a focus on strengths should lead to choosing goals that are overtaxing. It is the consideration of both strengths and weaknesses alike that increases the likelihood of choosing goals of medium difficulty which are known to be motivationally most effective (Atkinson, 1957; Heckhausen, 1991).

Future research may want to explore whether the self-defensiveness observed in the present study with low self-view individuals only holds if the importance of the critical self-aspect is very high (as is the case with intellectual abilities). Also, it may very well matter whether the critical self-aspect is perceived as malleable or not. Dweck (1996) differentiates between people holding an entity versus an incremental theory about their traits. Entity theorists believe their abilities to be rather stable and unchangeable, whereas incremental theorists believe that the level of their abilities can be much improved through learning. Accordingly, it seems possible that low self-view individuals are immunized against the observed self-defensiveness if they happen to adhere to incremental theories rather than entity theories. Recent findings by Trope, Gervey, and Bolger (2002), support these assumptions. In two experiments they observed that people with low abilities are able to overcome defensive self-evaluation if they believe that they have control over the diagnosed self-attribute (either by believing that the ability in question is changeable or that they have control over the expression of this ability).

When low self-view individuals are placed into an implemental mindset they fail to develop a selfenhancement orientation (i.e. we observed a balanced diagnostic information search on strengths and 
weaknesses). As the implementation of goals should be associated with encountering many hindrances and barriers in low self-view individuals (more so than in high self-view individuals), low self-view participants are in a particular need for persistence in goal pursuit. It is therefore very unfortunate that they focus on assessing their weaknesses and strengths in an accurate manner, rather than seeing their strengths in a positive light. This will definitely undermine the needed effort expenditure. Further research may want to explore what kind of low self-views are particularly detrimental to developing a positive outlook in the implemental mindset. Again, issues of the importance and perceived malleability of the specific self-aspect in question should play a role. However, it seems highly possible that individuals with extremely strong goal commitments are immunized against the positive illusion reducing effects of a low self-view.

A further issue for future research on mindset effects in low self-view individuals relates to the question of the critical level of low self-views: When do the described negative effects of deliberative and implemental mindsets on respective information search set in? In the present study, the low selfview participants were the 18 participants (out of 52) who scored in the lowest tertile on the rating scale assessing relative (in comparison to students of the same age) possession of the personal attribute of intellectual capability. Closer inspection showed that these participants still rated themselves as hardly worse than the average student (i.e. slightly more than $50 \%$ of the students were perceived as being better). This observation supports the assumption that positive illusions are quite pervasive (Taylor \& Brown, 1988); it is hard to find people who have very low (i.e. negative) self-views, and this may be one reason why past mindset studies on positive illusions commonly observed effects which, in the present study, were only observed for high self-view participants. With respect to the present study, this observation suggests that the negative effects of deliberative and implemental mindsets on information search emerge already in individuals with moderately low self-views; in individuals with very low (i.e. negative) self-views these negative effects should be even more easily demonstrated.

Finally, future research may want to address the question of whether information search on more general self-aspects (such as positive/negative self-concept or high/low self-esteem) is also differently affected by deliberative and implemental mindsets depending on a person's respective standing (i.e. low vs. high). Note that in the present study we only analysed a specific self-aspect (i.e. intellectual capability). As the deliberative and implemental mindsets are action-related mindsets, we assume that they affect information search for specific self-aspects more so than for general self-aspects, as specific self-aspects are comparatively more relevant to issues of action control (i.e. setting and implementing of specific behavioural goals). Indeed, research that succeeded in demonstrating moderator effects of personal attributes has always looked at rather specific personal attributes such as a person's achievement motive (Pucca \& Schmalt, 2001), social anxiety (Hiemisch et al., 2002), and interpersonal goal commitments (Gagné \& Lydon, 2001).

\section{CONCLUSION}

Participants who perceived themselves as high on a certain personal attribute (i.e. intellectual capability) demonstrated a self-assessment orientation in the deliberative mindset and a self-enhancing orientation in the implemental mindset, whereas participants with a low self-view did not adopt the selfevaluation orientations useful to goal selection and goal implementation, respectively.

From a self-regulatory perspective on goal setting (e.g. Oettingen, 1996; Oettingen, Pak, \& Schnetter, 2001) and goal implementation (Gollwitzer, 1999) this pattern of findings suggests that low self-view individuals would need to be taught how to appropriately solicit self-related information when deliberating potential goals versus implementing chosen goals. This would remove low self- 
view individuals from the bleak opportunity structure implied by their typical information search, as it only promotes inappropriate goal setting and unsuccessful goal implementation. In comparison to therapeutic approaches geared at directly changing people's low self-views (e.g. Watzlawick, Weakland, \& Fisch, 1974), the suggested intervention is more indirect by helping low self-view individuals to set and implement goals in a manner that produces results contradicting their low self-views. In our view, therefore, it seems wise to supplement traditional interventions aimed at changing low selfviews with interventions that aim at changing the action control strategies of low self-view individuals. Otherwise, low self-view individuals will continue to make experiences that confirm their original low self-views. The present perspective thus elucidates why therapeutic efforts that are exclusively geared at self-concept change are mostly futile (Lineham, Rosenthal, \& Kelley, 1977; Murray \& Holmes, 2000).

\section{REFERENCES}

Alloy, L. B., \& Abramson, L. Y. (1979). Judgements of contingency in depressed and nondepressed students: Sadder but wiser? Journal of Experimental Psychology: General, 108, 441-485.

Armor, D. A., \& Taylor, S. E. (2003). The effects of mindset on behavior: Self-regulation in deliberative and implemental frames of mind. Personality and Social Psychology Bulletin, 29, 86-95.

Aspinwall, L. G. (1998). Rethinking the role of positive affect in self-regulation. Motivation and Emotion, 22, 132.

Atkinson, J. W. (1957). Motivational determinants of risk taking behavior. Psychological Review, 64, 359-372.

Bandura, A. (1982). Self-efficacy mechanism in human agency. American Psychologist, 37, 122-147.

Baumeister, R. F., \& Cairns, K. J. (1992). Repression and self-presentation: When audiences interfere with selfdeceptive strategies. Journal of Personality and Social Psychology, 62, 851-862.

Brown, J. D. (1990). Evaluating one's abilities: Shortcuts and stumbling blocks on the road to self-knowledge. Journal of Experimental Social Psychology, 26, 149-167.

Brown, J. D., \& Dutton, K. A. (1995). The thrill of victory, the complexity of defeat: Self-esteem and people's emotional reactions to success and failure. Journal of Personality and Social Psychology, 68, 712-722.

Buunk, B. P. (1995). Comparison direction and comparison dimension among disabled individuals: Toward a refined conceptualization of social comparison under stress. Personality and Social Psychology Bulletin, 21, $316-330$.

Collins, R. L. (1996). For better or worse: The impact of upward social comparison on self-evaluation. Psychological Bulletin, 119, 51-69.

Colvin, C. R., \& Block, J. (1994). Do positive illusions foster mental health? An examination of the Taylor and Brown formulation. Psychological Bulletin, 116, 3-20.

Devine, P. G., Hirt, E. R., \& Gehrke, E. M. (1990). Diagnostic and confirmation strategies in trait hypothesis testing. Journal of Personality and Social Psychology, 58, 952-963.

Dunning, D. (1995). Trait importance and modifiability as factors influencing self-assessment and self-enhancement motives. Personality and Social Psychology Bulletin, 21, 1297-1306.

Dweck, C. S. (1996). Implicit theories as organizers of goal sand behavior. In P. M. Gollwitzer, \& J. A. Bargh (Eds.), The psychology of action: Linking cognition and motivation to action (pp. 69-90). New York: Guilford Press.

Gagné, F. M., \& Lydon, J. E. (2001). Mindset and relationship illusions: The moderation effects of domain specifity and relationship commitment. Personality and Social Psychology Bulletin, 27, 1144-1155.

Gollwitzer, P. M. (1990). Action phases and mind-sets. In E. T. Higgins, \& R. M. Sorrentino (Eds.), Handbook of motivation and cognition: Foundations of social behavior (Vol. 2, pp. 53-92). New York: Guilford Press.

Gollwitzer, P. M. (1999). Implementation intentions: Strong effects of simple plans. American Psychologist, 54, 493-503.

Gollwitzer, P. M. (2003). Why we thought that action mind-sets affect illusions of control. Psychological Inquiry, $14,259-267$. 
Gollwitzer, P. M., \& Bayer, U. (1999). Deliberative versus implemental mindsets in the control of action. In S. Chaiken, \& Y. Trope (Eds.), Dual-process theories in social psychology (pp. 403-422). New York: Guilford Press.

Gollwitzer, P. M., \& Kinney, R. F. (1989). Effects of deliberative and implemental mind-sets in the control of action. Journal of Personality and Social Psychology, 56, 531-542.

Gollwitzer, P. M., Heckhausen, H., \& Steller, B. (1990). Deliberative and implemental mind-sets: Cognitive tuning toward congruous thoughts and information. Journal of Personality and Social Psychology, 59, 1119-
1127 .

Heckhausen, H. (1991). Motivation and action. New York: Springer. Heckhausen, H., \& Gollwitzer, P. M. (1987). Thought contents and cognitive functioning in motivational vs.
volitional states of mind. Motivation and Emotion, 11, 101-120.

Hiemisch, A., Ehlers, A., \& Westermann, R. (2002). Mindsets and social anxiety: A new look at information procession bias. Journal of Behavior Therapy and Experimental Psychiatry, 33, 103-114.

Kunda, Z. (1990). The case for motivated reasoning. Psychological Bulletin, 108, 480-498.

Kwan, C. M. L., Love, G. D., Ryff, C. D., \& Essex, J. (2003). The role of self-enhancing evaluation in a successful life transition. Psychology and Aging, 18, 3-12. Lineham, K., Rosenthal, T. L., \& Kelley, J. (1977). Homogeneity and heterogeneity of problem class in modeling
treatment of fears. Behaviour Research \& Therapy, 15(2), 211-215. Mischel, W. (1973). Toward a cognitive social learning reconceptualization of personality. Psychological Review,
80, 252-253. Murray, S. L., \& Holmes, J. G. (1997). A leap of faith? Positive illusions in romantic relationships. Personality
and Social Psychology Bulletin, 23, 586-604.

Murray, S. L., \& Holmes, J. G. (2000). Seeing the self through a partner's eye: Why self-doubts turn into relationship insecurities. In A. Tesser, R. B. Felson, \& J. M. Suls (Eds.), Psychological perspectives on self and identity (pp. 173-197). Washington, DC: American Psychological Association.

Oettingen, G. (1996). Positive fantasy and motivation. In P. M. Gollwitzer, \& J. A. Bargh (Eds.), The psychology of action: Linking cognition and motivation to behavior (pp. 236-259). New York: Guilford.

Oettingen, G., Pak, H., \& Schnetter, K. (2001). Self-regulation of goal setting: Turning free fantasies about the future into binding goals. Journal of Personality and Social Psychology, 80, 736-753.

Paulhus, D. L. (1998). Interpersonal and intrapsychic adaptiveness of trait self-enhancement: A mixed blessing? Journal of Personality and Social Psychology, 74, 1197-1208.

global self-es Swann, W. B., Jr. (1989). From self-conceptions to self-worth: On the sources and structure of . Journal of Personality and Social Psychology, 57, 672-680.

Pomerantz, E. M., Saxon, J. L., \& Kenney, G. A. (2001). Self-Evaluation: The Development of sex differences. In G. B. Moskowitz (Ed.), Cognitive Social Psychology: The Princeton symposium on the legacy and future of
social cognition (pp. 59-74), New York: Mahwah.

Pucca, R M \& Schm.

and postdecisional action

Robins, R. W. \& Beer. J S.

Journal of Personality and Social Psychology, $80,340-352$ self: Short-term benefits and long-term costs.

Sedikides, C (1993). Ass Social Psychology, 80, 340-352.

Journal of Personality \& Social Psychology, 65(2), 317-338.

Sedikides, C., \& Skowronski, J. J. (2000). On the evolutionary of the sybor evaluation motives. In A. Tesser, R. B. Felson, \& J. M. Suls (Eds.), Psychological perspectives on self and identity. Washington, DC: American Psychological Association.

Sedikides, C., \& Strube, M. J. (1997). Self-evaluation: To thine own self be good, to thine own self be sure, to thine
own self be true, own self be true, and to thine own self be better. In M. A. Zanna (Ed.), Advances in Experimental Social
Psychology (Vol. 29, pp. 209-269). Psychology (Vol. 29, pp. 209-269). New York: Academic Press.

abilities: Accurate self-assessment versus biased self-enhanement Deichman, A. K. (1986). Self-evaluation of Psychology, 51, 16-25.

Swann, W. B., Jr. (1990). Bridge over troubled water. Psychological Inquiry, l(3), 211-212.

Swann, W. B., Jr. (1997). The trouble with change: Self-verification and allegiance to the self. Psychological
Science, 8, 177-183. Swann, W. B., Jr., \& Ely, R. J. (1984). A battle of will: Self-verification versus behavioral confirmation. Journal of
Personality and Social Psychology, 46, 1287-1302. 
Swann, W. B., Jr., Pelham, B. W., \& Chidester, T. R. (1988). Change through paradox: Using self-verification to alter beliefs. Journal of Personality \& Social Psychology, 54(2), 268-273.

Swann, W. B., Jr., Stein-Seroussi, A., \& Giesler, R. B. (1992). Why people self-verify. Journal of Personality and Social Psychology, 62, 392-401.

Taylor, S. E., \& Brown, J. D. (1988). Illusion and well-being: A social psychological perspective on mental health. Psychological Bulletin, 103, 193-210.

Taylor, S. E., \& Gollwitzer, P. M. (1995). Effects on midset on positive illusions. Journal of Personality and Social Psychology, 69, 213-226.

Taylor, S. E., Aspinwall, L. G., Guilano, T., Dakof, G. A., \& Readon, K. (1993). Storytelling, social comparison and coping. Journal of Applied Social Psychology, 9, 703-733.

Taylor, S. E., Neter, E., \& Wayment, H. A. (1995). Self-evaluation processes. Personality and Social Psychology Bulletin, 21, 1278-1287.

Taylor, S. E., Kemeny, M. E., Reed, G. M., Bower, J. E., \& Gruenewald, T. L. (2000). Psychological resources, positive illusions, and health. American Psychologist, 55, 99-109.

Trope, Y. (1986). Self-enhancement and self-assessment in achievement behavior. In R. M. Sorrentino, \& E. T. Higgins (Eds.), Handbook of motivation and cognition: Foundations of social behavior (pp. 350-378). New York: Guilford Press.

Trope, Y., \& Bassok, M. (1982). Confirmatory and diagnosing strategies in social information gathering. Journal of Personality and Social Psychology, 43, 22-34.

Trope, Y., \& Liberman, A. (1996). Social hypothesis testing: Cognitive and motivational mechanisms. In E. T. Higgins, \& A: W. Kruglanski (Eds.), Social psychology: Handbook of basic principles (pp. 239-270). New York: Guilford Press.

Trope, Y., \& Neter, E. (1994). Reconciling competing motives in self-evaluation: The role of self-control in feedback seeking. Journal of Personality and Social Psychology, 66, 646-657.

Trope, Y., \& Pomerantz, E. M. (1998). Resolving conflicts among self-evaluative motives: Positive experiences as a resource for overcoming defensiveness. Motivation and Emotion, 22, 53-72.

Trope, Y., Ferguson, M., \& Raghunathan, R. (2001). Mood as a resource in processing self-relevant information. In J. P. Forgas (Ed.), Handbook of affect and social cognition (pp. 256-274). Mahwah, NC: Erlbaum.

Trope, Y., Gervey, B., \& Bolger, N. (2002). The role of perceived control in overcoming defensive self-evaluation. Journal of Experimental Social Psychology, 39, 407-419.

Watzlawick, P., Weakland, J., \& Fisch, R. (1974). Chance: Principles of problem formation and problem resolution. New York: Norton.

Wayment, H. A., \& Taylor, S. E. (1995). Self-evaluation processess: Motives, information use, and self-esteem. Journal of Personality, 63, 729-757.

Wheeler, L. (1966). Motivation as a determinant of upward comparison. Journal of Experimental Social Psychology, 2(Suppl. 1), 27-31.

Wright, S. S. (2000). Looking at the self in a rose-colored mirror: Unrealistically positive self-views and academic performance. Journal of Social and Clinical Psychology, 19, 451-462. 